\title{
MUC1 SP Vaccine
}

National Cancer Institute

\section{Source}

National Cancer Institute. MUC1 SP Vaccine. NCI Thesaurus. Code C148171.

A therapeutic cancer vaccine comprised of a synthetic, 21-mer long peptide (LP) derived from the entire signal peptide (SP) domain of the tumor-associated antigen (TAA) mucin 1 (MUC1), with potential immunomodulating and antineoplastic activities. Upon intradermal administration, MUC1 SP vaccine may stimulate the host immune system to mount robust cytotoxic T-lymphocyte (CT L) and B-cell responses against MUC1expressing tumor cells, resulting in tumor cell apoptosis and decreased tumor growth. MUC1 is overexpressed on many tumor cell types. 